\title{
Specific Features of Mixed Culture of Invertebrates Maintained under Laboratory Conditions
}

\author{
Tamara I. Pisman * \\ Institute of Biophysics of Siberian Branch of Russian Academy of Science, \\ 50 Akademgorodok, Krasnoyarsk, 660036 Russia ${ }^{I}$
}

Received 1.06.2009, received in revised form 8.06.2009, accepted 15.06.2009

\begin{abstract}
Competition among invertebrates was studied in mixed culture (the ciliates Paramecium caudatum and Paramecium bursaria and the rotifer Brachionis plicatilis) under laboratory conditions. The invertebrates were fed on various food sources: 1) Chlorella biomass and 2) biomasses of bacteria and yeast. The P.bursaria - Chlorella condutrix endosymbiosis was used a natural model of a simple biotic cycle. P.caudatum was found to be a poor competitor: even when the initial percentage of P.caudatum cells was large and there was no food limitation, this ciliate had been expelled by the end of the experiment. The main reason for the low competitive ability of P.caudatum in the studied system was likely the inhibiting effect of invertebrates' metabolites. The outcome of the competition between the ciliate P. bursaria and the rotifer B. plicatilis was different depending upon the food source: 1) Chlorella or 2) bacteria and yeast. When fed on Chlorella, P. bursaria was a better competitor than B. plicatilis. With bacteria and yeast used as food, the opposite outcome of competition was observed: the competitive ability of B. plicatilis was better than that of P. bursaria. It was assumed that due to turbidity of the culture solution in experiments with bacteria and yeast used as food, the zoochlorella photosynthesis rate decreased and, hence, the P. bursaria - zoochlorella symbiosis became less competitive. Analysis of experimental results of $P$. bursaria and P. caudatum single species cultures in the light and in the dark, with bacteria used as a food source, confirmed that assumption. The results of the experiments confirmed the beneficial role of symbiotic relationships of the ciliate P. bursaria and zoochlorella. The number of symbiotic units in the light reached 220 units $/ \mathrm{ml}$, while in the dark it was much smaller. The P. caudatum number remained practically the same in the light and in the dark.
\end{abstract}

Keywords: competition, experimental aquatic system, invertebrates.

\section{Introduction}

Competition among invertebrates is of both theoretical and practical interest. General ecology has mainly addressed the competition for food (Cheng et al., 2004). As known closely related organisms with similar modes of existence cannot inhabit the same place, this is the Gause's competitive exclusion principle.
It was shown that the ciliate Paramecium bursaria (Ehrenberg, 1831) united in one cycle with Chlorella had a higher competitive ability than Paramecium caudatum (Ehrenberg, 1833) (Pisman and Somova, 2003). With any initial percentage of the ciliates in the mixed culture, the end portion of P. bursaria reached 90-99 -, which was significantly higher than the end portion of the P. caudatum population.

\footnotetext{
* Corresponding author E-mail address: pech@ibp.ru
}

(C) Siberian Federal University. All rights reserved 
Some published data suggest the leading role of external metabolites in successions. It has been shown that the action of a specific inhibitor is very selective and affects different species in a mixed community, thus determining the result of competition (Lundy et al., 1984). An experimental and mathematical model of interactions between invertebrates (the ciliate $\mathrm{P}$. caudatum and the rotifer B. plicatilis) has been studied in the «producer - consumer» aquatic biotic cycle with spatially separated components (Pisman and Bogdanova, 2004). The model described the dynamics of the mixed culture of ciliates and rotifers in the «consumer» component feeding on the mixed algal culture of the "producer» component. Metabolites of the alga Scenedesmus have been found to produce an adverse effect on the reproduction of the ciliate P.caudatum. In the «producer - consumer» biotic cycle coexistence proved to be impossible in the mixed culture of invertebrates of the «consumer» component. The ciliate P.caudatum was driven out by the rotifer B. plicatilis (Pisman et al., 2002).

In the experimental laboratory system the outcome of competition can be affected by a number of other factors (nutrient limitation, variations in $\mathrm{pH}$ of the environment, accumulation of metabolism products, etc.) (Norberg and DeAngelis, 1997).

There are publications on interrelationships among littoral rotifers. The effect of different densities of algae and rotifers on the outcome of their competition has been investigated by S. Sarma and S. Nandini (2001). The benthic protozoa have been studied along a transect in the eastern Mediterranean Sea from the Ionian to the Levantine Sea (Hausmann et al., 2002). The studied species included picophagous species, which feed mostly on bacteria, as well as nanoand microphagous species, which generally feed on protists, suggesting the existence of several trophic levels within the deep sea microbial food web. Thus, competition of invertebrates in both experimental and natural systems is an important problem for experimental and theoretical aquatic ecology.

The purpose of this study was to study a mixed culture of invertebrates (Paramecium bursaria (Ehrenberg, 1831), Paramecium caudatum (Ehrenberg, 1833) and Brachionus plicatilis (Muller, 1786) in an experimental system and to get an insight into the reasons responsible for the outcome of their competition (coexistence or exclusion).

\section{Materials and Methods}

Invertebrates used in the study were the ciliate Paramecium caudatum, the rotifer Brachionus plicatilis and a symbiosis of the ciliate Paramecium bursaria and its endosymbiont, zoochlorella Chlorella condutrix. The vital functions of the «P. bursaria - zoochlorella» symbiosis were maintained by zoochlorella photosynthesis.

Flows and interactions in the mixed culture of invertebrates with Chlorella used as food are schematically presented in Fig. 1. The ciliate $P$. bursaria contains zoochlorella and consumes carbohydrates and oxygen released by zoochlorella during photosynthesis. Under light-deficient conditions it can also consume Chlorella and bacteria. The ciliate P. caudatum can feed on yeast, bacteria, and Chlorella. The rotifer $B$. plicatilis can feed on algae, bacteria, yeast, and detritus (Sarma and Nandini, 2001). In this experiment invertebrates were grown on Chlorella. During the course of their metabolism paramecia released nitrogen, which was then consumed by Chlorella and zoochlorella. Part of dead invertebrates became detritus and provided a substrate for multiplication of rotifers (Gulati and DeMott, 1997).

The invertebrates were grown in the LozinaLozinsky synthetic medium supplemented with 


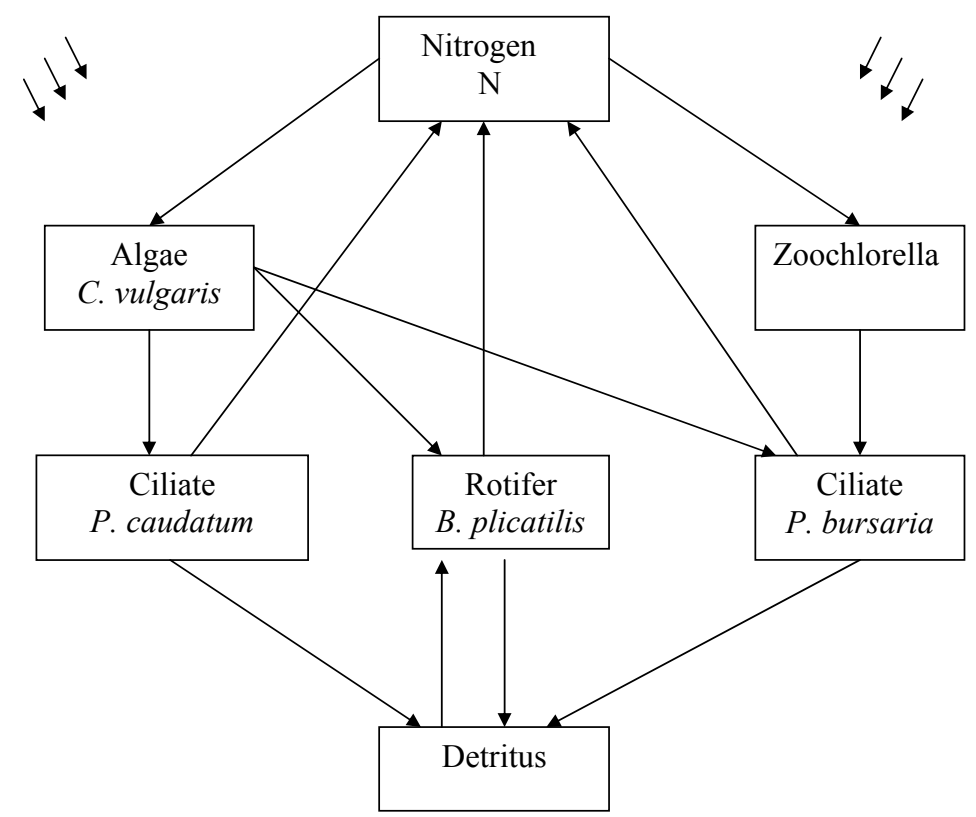

Fig.1. Scheme of flows and interactions in the mixed culture of invertebrates in an experimental laboratory aquatic system

biomass of yeast, bacteria or Chlorella as food sources (Kokova, 1982). Bacteria were cultivated on rice, which was added to the medium at the beginning of the experiment (Hausmann, 1985). Cultivation of invertebrates was performed in 500-ml flasks under natural light conditions during 74 days, day length was about 16 hours, temperature was $18{ }^{\circ} \mathrm{C}$. The numbers of the ciliates and rotifers were determined by direct count in Bogorov's chamber (standard deviation $10-$ ) (Kokova, 1982).

\section{Results}

The dynamics of the mixed culture of invertebrates ( $P$. bursaria, P. caudatum and $B$. plicatilis) in the experimental laboratory aquatic system was investigated for two cases: with 1) Chlorella and 2) bacteria and yeast used as food.

Fig. 2 and 3 show the dynamics of invertebrates in the mixed culture for 74 days in experiments with different initial proportions of competitors, grown on Chlorella.P. caudatum and the rotifer initially amounted to about $14-$ and $P$. bursaria to 72 - (Fig. 2). At Day 15, P. caudatum was expelled; at Day 24, stable coexistence was established between P. bursaria (about $65-$ ) and the rotifer (about $35-$ ). The final outcome of the competition of invertebrates in the variant with different initial proportions (Fig. 3) was similar to the outcome of the competition shown in Fig. 2. Although the initial fraction of $P$. caudatum was considerably larger and amounted to about $80-$, at Day 60 this ciliate was also expelled. P. bursaria $(1-)$ was added later, at Day 14. Yet, stable coexistence between $P$. bursaria (about $60-$ ) and the rotifer (about $40-$ ) was established.

The dynamics of the mixed-culture invertebrates grown on bacteria and yeast (without Chlorella) is shown in Fig. 4. The best food for $P$. caudatum were the bacterium Bacillus subtilis and a mixture of Bacillus subtilis and yeast. However, in this experiment, the ciliate $P$. caudatum was a poor competitor too. Initially, P. caudatum constituted about $80-$, but at Day 70 it was completely expelled. However, the outcome of the competition between the rotifer and 


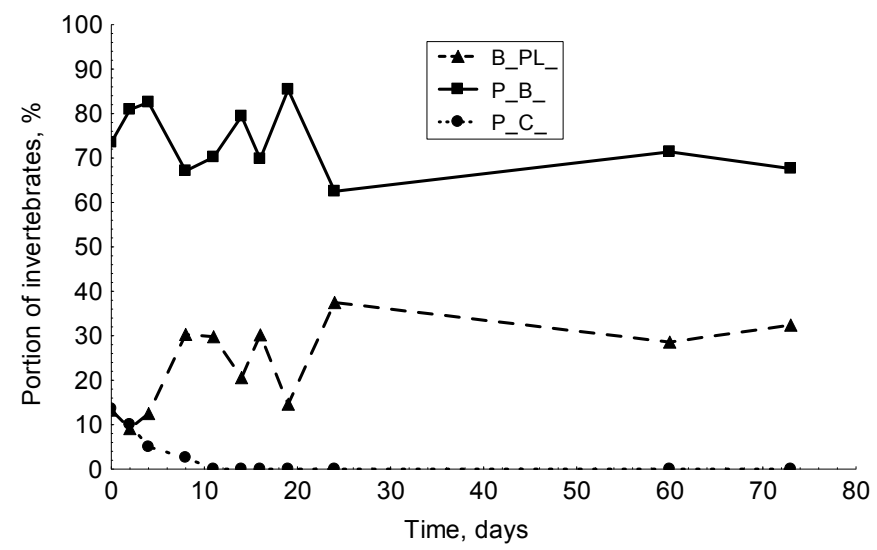

Fig.2. Dynamics of invertebrates ( - of the total number), with the initial fraction of $P$. caudatum in the mixed culture amounting to $14-$, grown on Chlorella

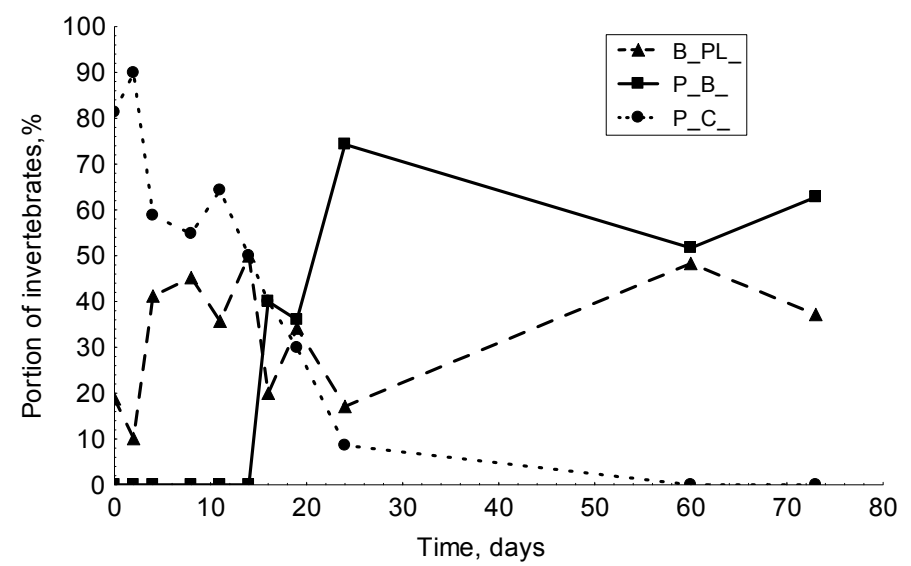

Fig.3. Dynamics of invertebrates ( - of the total number), with the initial fraction of $P$. caudatum in the mixed culture amounting to $80-$, grown on Chlorella

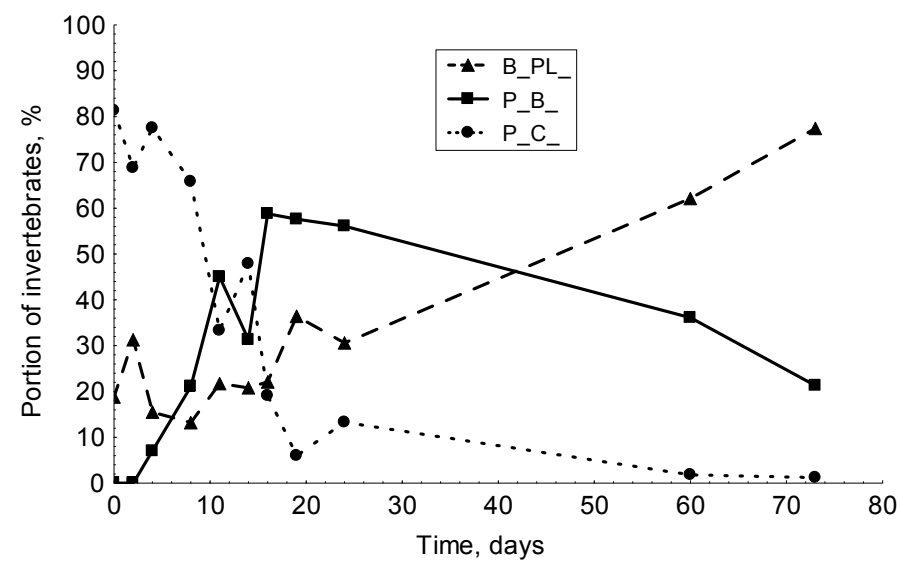

Fig.4. Dynamics of invertebrates ( - of the total number), with the initial fraction of P. bursaria in the mixed culture amounting to $1-$, grown on bacteria and yeast 
P. bursaria grown on bacteria and yeast (Fig. 4) was opposite to that observed in experiments with the medium containing Chlorella (Fig. 2 and 3). At Day 40, the fractions of P. bursaria and B. plicatilis became equal. At Day 74, the rotifer amounted to 75 -, while P. bursaria dropped to 25 -. In this experiment, the culture medium was turbid, in contrast to the experiment with Chlorella-supplemented medium. Thus, as less light penetrated into the medium, zoochlorella photosynthesis rate decreased, and P. bursaria became less competitive than the rotifer.

To verify this assumption, we studied competition of invertebrates in the mixed culture consisting of two components (the rotifer and $P$. bursaria) (Fig. 5). The outcome of the competition was similar to that in the three-component system (Fig. 4). At the beginning of the experiment, when the culture medium was transparent, the fraction of $P$. bursaria had increased to reach $99-$. Then, as the culture medium became more turbid, the fraction of $P$. bursaria decreased and at Day 74 it dropped to 35-40 -, while the rotifer amounted to $60-65-$.

Analysis of experimental results of growing P. bursaria (Fig. 6) and P. caudatum (Fig. 7) single species cultures in the light and in the dark in the medium supplemented with bacteria confirmed the beneficial role of symbiotic relationships. The number of symbiotic units in the light (Fig. 6) reached 220 units $/ \mathrm{ml}$, while in the dark it was much smaller. The P. caudatum number (Fig. 7) remained practically the same in the light and in the dark.

\section{Discussion}

As multiplication of $P$. bursaria that was symbiotic with zoochlorella in the light occurred irrespectively of the additional food source (Chlorella), in the mixed culture of invertebrates the main competitors for Chlorella were the rotifer and $P$. caudatum. The rotifer could also feed on detritus, but at the beginning of the experiment it must have preferred Chlorella, since this alga is known to be the most favorable food for $B$. plicatilis multiplication.

Although there were two food sources (Chlorella and detritus) for two types of invertebrates (B. plicatilis and P. caudatum), $P$. caudatum was found to be a very poor competitor under these conditions. One of the reasons could be its inhibition by waste products of metabolism. As reported in the literature, the growth of the protozoa culture is significantly affected by waste products of their own metabolism (Kokova, 1982). The author suggested that the termination of growth was caused by enhanced amounts of waste products of metabolism in the medium. This explanation is in good agreement with the experiments that revealed the influence of metabolites on Paramecium.

The advantages of the $P$. bursaria symbiotic unit (the ciliate - zoochlorella) are quite obvious (Yellowlees et al., 2008). The symbionts can supply the host with products of photosynthesis and molecular oxygen, which is necessary for oxidative processes, while the ciliate, which is motile, can increase the light supply necessary for the microalga and provide it with ammonium compounds - mineral substrate essential for the growth of chlorella. These compounds are the ciliate's metabolites, toxic to it (Barkhatov et al., 1998).

Partners' relationships can rather easily change from mutualistic to antagonistic (and back), depending on the environmental conditions. For instance, symbiosis of the freshwater hydra and Chlorella improves development of the host in the light and in the absence of carbon compounds, when the products of photosynthesis supplied by the endosymbiont are the only food source for the host. However, the development of the hydra transferred to the dark is suppressed because photosynthesis is stopped and the endosymbiont 


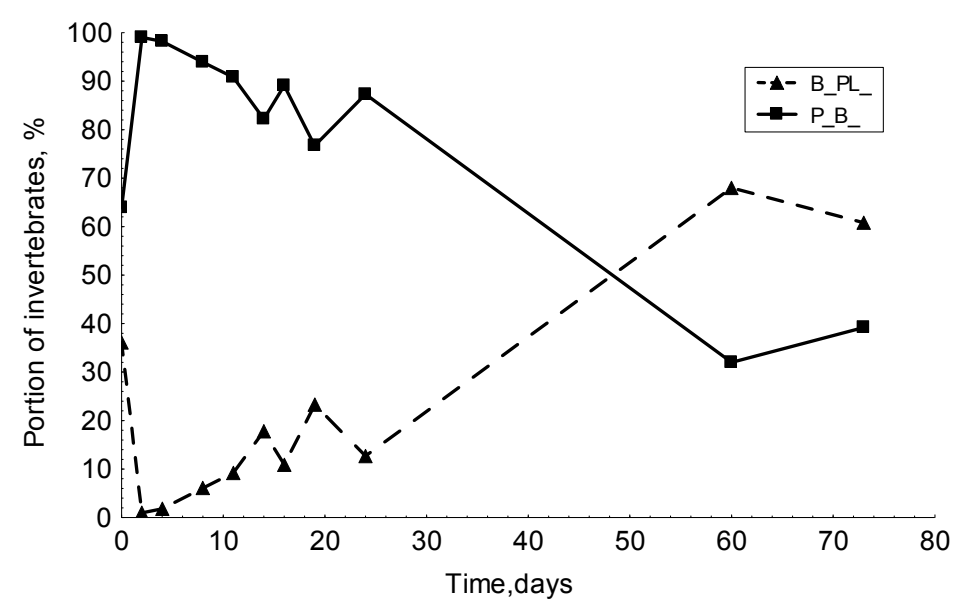

Fig.5. Dynamics of invertebrates ( - of the total number), with the initial fraction of $P$. bursaria in the mixed culture amounting to $65-$, grown on bacteria and yeast

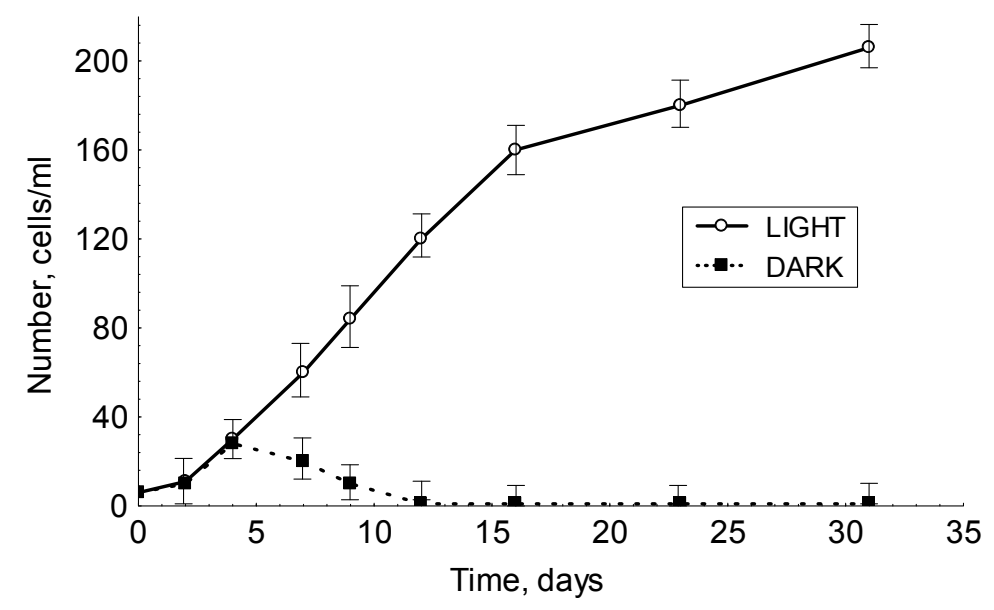

Fig.6. Growth of the P. bursaria - zoochlorella symbiosis in the light and in the dark

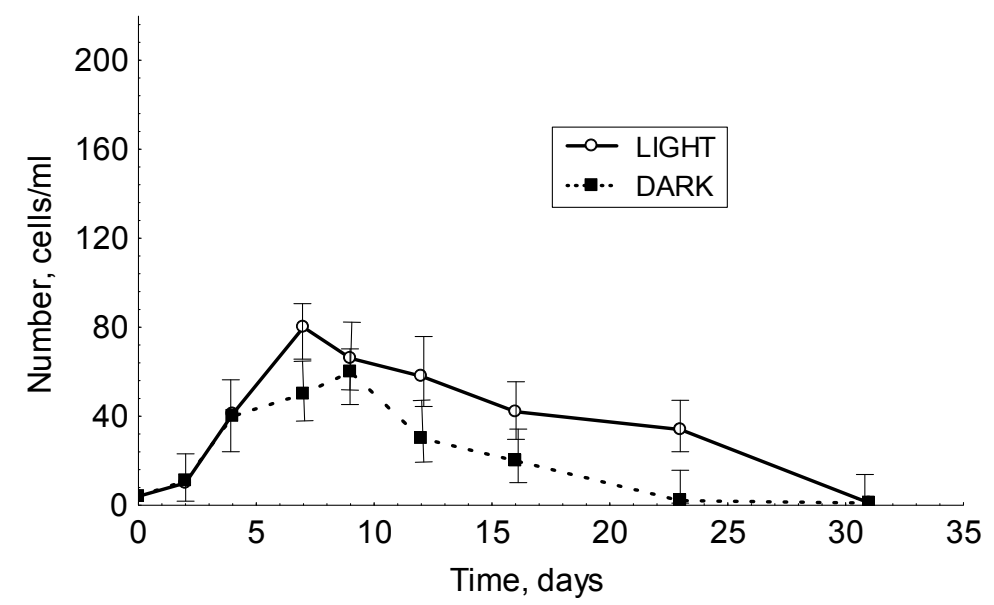

Fig.7. Growth of the ciliate $P$. caudatum in the light and in the dark 
has to consume the host's metabolites (Provorov, 2001). Intracellular symbionts of paramecia (Caedibacter) can be both mutualists and antagonists for their host, depending upon feeding conditions (Pond et al., 1989).

Several studies are available on the interspecific relations among zooplankton (Hagivara et al., 1995; Jung et al., 1997). Controversial results were reported by Hagivara et al. (1995) and Jung et al. (1997) on the interspecific relations between rotifers (Brachionus rotundiformis) and copepods (Tigriopus japonicus). Hagivara et al. (1995) have reported that the copepod T. japonicus did not affect rotifer growth, while T. japonicus grew better with rotifers than when cultured alone. On the other hand, Jung et al. (1997) have showed that contamination of rotifer cultures with T. japonicus strongly suppressed $B$. rotundiformis population growth when compared to $B$. rotundiformis single species cultures. At the same time, the growth of $T$. japonicus was better when cultured alone than when the two species were kept in mixed cultures.

M. Jung and coauthors (1997) have suggested that the interspecific relations between rotifers and copepods could be influenced by co-existing aquatic bacteria occurred in the cultures. A subsequent study demonstrated that the presence or absence of bacteria in the aquatic environment can alter the relationship between species (Jung and Hagiwara, 2001). Co-existing bacteria had a pivotal impact on the interspecific relations between $B$. rotundiformis and T. japonicus in experimental conditions.

Recently, a competition experiment between the rotifer Brachionus rotundiformis and the ciliate Euplotes vannus has been carried out (Cheng et al., 2004). The ciliate was inoculated at three stages of the rotifer growth curve: the lag phase, the logarithmic growth phase and the stationary phase. When feeding on the alga
Tetraselmis tetrathele, the ciliate numbers increased and the rotifer growth was suppressed. The interference with rotifer growth was stronger in the lag and stationary phases than in the logarithmic growth phase. In contrast, when feeding on the alga Nannochloropsis oculata, the ciliate did not increase and the rotifer growth was similar to the control. The fundamental importance of quantifying population density effects in natural and laboratory populations has been well recognized (Snell et al., 2001). Density effects in laboratory rotifer populations were higher than density effects in natural populations. Density effects in laboratory populations are due to food limitation, autotoxicity or to their combined effects. The cited above work on the experiments with $B$. rotundiformis demonstrated the absence of autotoxicity at densities as high as $865 \mathrm{ml}^{-1}$, a much higher density than observed in natural populations. Therefore, the authors have concluded that food limitation rather than autotoxicity plays a major role in regulating natural rotifer populations.

Thus, the outcome of competition of invertebrates in prolonged batch culture in the experimental system can depend upon a number of factors: food source, transparency of the culture medium, accumulation of waste products of metabolism, etc. Ecological factors, such as water temperature, $\mathrm{pH}$, dissolved oxygen, biomass of cyanobacteria, diatoms, greens and euglenoids were considered as possible causes of the mortality of different zooplankton species (Dubovskaya, 2008). These factors should be taken into account when designing experimental and theoretical closed and open ecosystems.

\section{Conclusion}

Thus, experimental studies of competition in the mixed culture of invertebrates (Paramecium bursaria, Paramecium caudatum and Brachionus plicatilis) with 1) Chlorella and 2) bacteria and 
yeast used as food showed poor competitive ability of the ciliate $P$. caudatum. Whatever the initial proportions of invertebrates, by the end of the experiment $P$. caudatum was expelled.

The study showed that the outcome of the competition between the ciliate $P$. bursaria and the rotifer $B$. plicatilis could be different depending upon the food source: 1) Chlorella or 2) bacteria and yeast. Fed on Chlorella, P. bursaria was a better competitor than B. plicatilis. With bacteria and yeast used as food, the opposite outcome of competition was observed: the competitive ability of $B$. plicatilis was better than that of $P$. bursaria.

\section{Acknowledgments}

This study was supported by the grant of the Russian Foundation for Basic Research (No. 09-07-00026).

\section{References}

Barkhatov Y.V., Gubanov V.G., Sazonova V.E. (1998) On the cooperative effect of the organic and mineral substrates on growth rates of symbionts in the Paramecium bursaria-zoochlorella symbiotic unit. Ekologiya (Ecology). 4: 327-329 (in Russian).

Cheng S.H., Aoki S., Maeda M., Hino A. (2004) Competition between the rotifer Brachionus rotundiformis and the ciliate Euplotes vannus fed on two different algae. Aquaculture. 241: 331-343.

Dubovskaya O.P. (2008) Evaluation of possible causes of non-predatory mortality of crustacean zooplankton in a small Siberian reservoir. Journal of Siberian Federal University. Biology 1: 3-18.

Gulati R.D., DeMott W.R. (1997) The role of food quality for zooplankton: remarks on the stateof-the-art, perspectives and priorities. Freshwater Biol. 38: 753-768.

Hagiwara A., Jung M.-M., Sato T., Hirayama K. (1995) Interspecific relation between marine rotifer Brachionus rotundiformis and zooplankton species contaminating in the rotifer mass culture tank. Fish. Sci. 61: 623-627.

Hausmann K. (1985) Protozoologie. New York: Georg Thieme Verlag. 334 p.

Hausmann K., Hulsmann N., Polianski I., Schade S. and Weitere M. (2002) Composition of benthic protozoan communities along a depth transect in the eastern Mediterranean Sea. Deep Sea Research Part I: Oceanographic Research Papers. 49 (11): 1959-1970.

Jung M.-M., Hagivara A. (2001) The effect of bacteria on interspecific relationships between the euryhaline rotifer Brachionus rotundiformis and the harpacticoid copepod Tigriopus japonicus. Hydrobiologia. 446/447: 123-127.

Jung M.-M., Hagivara A., Hirayama K. (1997) Interspecific interactions in the marine rotifer microcosms. Hydrobiologia. 358: 121-126.

Kokova V.E. (1982) Nepreryvnoye kultivirovaniye bespozvonochnykh (Continuous cultivation of invertebrates). Novosibirsk: Nauka. 168 p. (in Russian).

Lundy P., Wurster C.F., Roucland R.G. (1984) A two-species marine algal bioassay for detecting aquatic toxicity of chemical pollutants. Water Res. 18: 187-194.

Norberg J., DeAngelis D. (1997) Temperature effects on stocks and stability of a phytoplanktonzooplankton model and the dependence on light and nutrients Ecol. Model. 95: 75-86.

Pisman T.I., Bogdanova O.N. (2004) An experimental study and a mathematical model of interactions in the mixed culture of invertebrates and algae in the «producer-consumer» aquatic biotic cycle. Biofizika (Biophysics) 49 (6): 1112-1117 (in Russian).

$$
-189-
$$


Pisman T.I., Bogdanova O.N., Kalambet N.S. (2002) Specific features of interactions in a mixed culture of algae and invertebrates in the "producer - consumer» aquatic biotic cycle.// Sibirskii ekologicheskii zhurnal (Siberian Ecological Journal) 6: 657-662 (in Russian).

Pisman T.I., Somova L.A. (2003) Competition of the natural and manmade biotic cycles in the closed aquatic system. Adv. Space Res. 31( 7): 1757-1761.

Pond F.R., Gibson I., Lalucat J., Quackenbush R.L. (1989) R-body producing bacteria. Microb. Rev. 53(1): 25-67.

Provorov N.A. (2001) Genetic-evolutionary foundations of symbiosis studies. Zhurnal obshchei biologii (Journal of General Biology) 62(6): $472-495$ (in Russian).

Sarma S.S.S., Nandini S. (2001) Life table demography and population growth of Brachionus variabilis Hempel, 1896 in relation to Chlorella vulgaris densities. Hydrobiologia. 446/447: 75-83.

Snell T.W., Dingmann B.J., Serra M. (2001) Density - dependent regulation of natural and laboratory rotifer populations. Hydrobiologia. 446/447: 39-44.

Yellowlees D., Rees T.A.V., Leggat W. (2008) Metabolic interactions between algal symbionts and invertebrate hosts. Plant, Cell and Environment. 31(5): 679-694. 